\title{
Culturas, Enfermedades y Medicinas. Reflexiones sobre la Atención de la Salud en Contextos Interculturales de Argentina, Anatilde Idoyaga Molina, Ediciones IUNA, Buenos Aires 2003.
}

\section{Comentado por Mercedes Saizar* e Ivania Disderi*}

Este libro consta de tres capítulos y veinticuatro subcapítulos, donde la autora, desde una perspectiva fenomenológica y hermenéutica, plantea el conflicto que existe entre la medicina tradicional y la clínica biomédica, las diferentes nociones en torno a la etiología y manifestaciones de la enfermedad, presentando las diferentes estrategias que llevan adelante los usuarios en su búsqueda de salud. Propone una clasificación de la enfermedad comprendida a partir de diferentes tipos de desequilibrios, basándose en las vivencias, ideas y nociones de campesinos del Noroeste Argentino (NOA), macro área que define con suficiente homogeneidad cultural como para ser abordada como una unidad.

\section{Primera Parte: Las ofertas terapéuticas: complemen- tariedades y conflictos}

Los datos utilizados provienen de numerosos trabajos de investigación que la autora ha realizado en la zona del NOA. Idoyaga Molina presenta la perspectiva de los nativos en torno a sus vivencias de enfermedad, a través de la recolección de caminos terapéuticos, así como de entrevistas abiertas, extensas y recurrentes a informantes claves y calificados, entre quienes figuran tanto especialistas de la medicina tradicional, como los dolientes y sus familiares. A partir de dicha investigación realizada con usuarios de la salud, tanto en población campesina, mestiza como urbana, de diversos niveles socioeconómicos y educativos, la autora analiza la incidencia de los factores representacionales en la selección de diversas medicinas, desde la perspectiva del usuario.

Describe según regiones geográficas las preferencias terapéuticas de los usuarios y su sustento en las diversas nociones como la de persona, las entidades que la conforman, la enfermedad, la salud y la terapia. Representaciones, la mayoría de las veces, contradictorias con las de la biomedicina, modelo dominante en la atención de la salud desde las políticas oficiales. Observa, asimismo, que:

Sin tomar en consideración las leyes vigentes que limitan el ejercicio de la medicina a los biomédi- cos, la mayor parte de la población recurre a medicinas diversas (p. 24).

De acuerdo a la autora, funciona en la práctica un sistema etnomédico, es decir, la atención de la salud mediante el traslapo entre la biomedicina, las medicinas tradicionales y el autotratamiento o medicina casera (Good 1987:23-24), a las que se agregan en su región de estudio las medicinas religiosas y de alternativa (Idoyaga Molina 1997a y 1998).

La autora constata así la existencia de una práctica de combinación de medicinas, tanto en la población indígena y campesina como en la urbana, siendo los pacientes de mayor ingreso y mayor nivel educacional, quienes concurren a la mayor gama de posibilidades terapéuticas.

Refiriéndose a las estrategias de complementariedad terapéutica describe dos niveles: el primero implementado en el marco de las políticas de salud de los gobiernos de acuerdo a las sugerencias realizadas por la OMS, reflejándose en nuestro país, en la figura del agente sanitario.

Referente al segundo nivel, describe extensamente las estrategias desarrolladas por los pacientes a fin de evitar la censura y descalificación de los biomédicos por la utilización de otras medicinas en la búsqueda de salud o por la referencia a otros saberes y representaciones.

Destaca que no solo el paciente es censurado, sino los especialistas perseguidos por ejercer la terapia, motivo por el cual desarrollan también estrategias de adaptación que les permitan llevar adelante su terapia, evitando los enfrentamientos con la biomedicina.

...el choque de saberes entre las nociones de enfermedad, de terapia y las representaciones asociadas que sustentan los biomédicos y, en general, los profesionales de la salud, con las nociones y representaciones que sustentan los pacientes, en especial aborígenes, mestizos y campesinos, muchos de ellos inmigrantes a las ciudades (p. 49).

La visión cientificista y biologista prima en la atención de la salud, descalificando y desvalorizando al usuario en términos sociales, en cuanto a sus conoci-

* Becaria Doctoral Interna. Centro Argentino de Etnología Americana. Consejo Nacional de Investigaciones Científicas y Técnicas. Instituto Universitario Nacional del Arte, Área Transdepartamental de Folclore. 
mientos y prácticas, lo que los biomédicos entienden y perciben como enfermedad no es más que una representación posible entre muchas otras, pero que se ha convertido en la única posible para la biomedicina dominante y, consecuentemente, no la perciben como representación sino que la perciben como la aproximación racional, la verdad científica en la práctica de la salud motivos que les permiten desacreditar a las otras representaciones o transformarlas en dimensiones accesorias (p. 60).

Idoyaga Molina señala que una de las razones de ser de la antropología de la enfermedad o antropología médica, de acuerdo a Laplantine (1999: 336) es poner en evidencia lo que no se dice en el discurso biomédico, es decir, mostrar que la práctica biomédica se fundamenta e inspira en un discurso que tiende a hacer ver a la biomedicina como un paradigma insuperable, autosuficiente y completamente neutro en la atención de la salud.

A criterio de la autora, son estos factores los que impiden la puesta en práctica de las recomendaciones de organismos internacionales ad hoc, tal como la Organización Mundial de la Salud, que prevén la incorporación de especialistas de diversas medicinas en los espacios de atención de la salud bajo un plano de igualdad.

\section{Segunda Parte: Ideas sobre la enfermedad en el NOA y Cuyo}

En el siguiente capítulo, la autora procura llevar a cabo un análisis exhaustivo de la noción de enfermedad en sociedades tanto indígenas, mestizas como campesinas y aun en los centros urbanos. Demuestra de qué manera las representaciones culturales inciden en la vida cotidiana, cómo las percepciones y preferencias de los campesinos reflejan la eficacia de determinadas técnicas y las falacias de otras.

En cuanto al concepto de enfermedad, Idoyaga Molina involucra distintos tipos de desequilibrios que se originan a partir de diferentes etiologías, las cuales incluyen causas naturales, emocionales, sociales, ambientales y religioso rituales y, por consecuencia, abarcan representaciones de carácter mítico como así también al poder tanto de la naturaleza como de los nexos sociales.

Pretende desde los propios conocimientos y sin dejar de lado los testimonios de los diferentes informantes, manifestar cada uno de los desequilibrios y a su vez las enfermedades que pueden producir, según cuál fuere el origen y las causas de las mismas. Para concretar dicho estudio no podría obviar el análisis de cada uno de los taxa vernáculos, de los síntomas, el diagnóstico, los procedimientos y por supuesto el rol que desempeñan los especialistas de las diferentes medicinas.

Desequilibrios Orgánicos. Se explican por causas naturales, entre las que la autora menciona los desbalances térmicos, los desbalances alimenticios, golpes y esfuerzos. Las terapias utilizadas incluyen la medicina ca- sera, es decir, las recetas de origen vegetal y la cura de palabra. Estas acciones se complementan con el poder, utilizado por la autora en términos de sagrado, de los elementos utilizados en los preparados y el de los rezos o plegarias que evocan figuras y símbolos del catolicismo (p. 74).

Desequilibrios entre las entidades que conforman la persona. El Susto. Estos se originan en la desarmonía entre el cuerpo y el espíritu, la que puede ser causada por las experiencias de pánico o por el tratamiento inapropiado de la materia fecal y el orín. Además del susto que es la enfermedad típica, la autora incluye en esta categoría a la agarradura o pilladura, dolencias que aluden a la pérdida del alma, la que es extraída por una deidad.

Desequilibrios Sociales. Se generan en la interacción social o en la pérdida de vínculos familiares y sociales. Idoyaga Molina incluye dentro de los mismos al ojeo u ojeadura, la envidia, la brujería y la tiricia, entendida ésta como el mal resultante de la añoranza o tristeza por la pérdida de los afectos más cercanos.

Desequilibrios espacio-ambientales. El mal aire. El mal aire puede atribuirse a causas naturales tales como los desbalances térmicos. Esta enfermedad penetra en el cuerpo cuando uno permanece o pasa por lugares inadecuados o de energía negativa. Esta potencia negativa es una sustancia que se impregna por contacto con el medio y se evidencia en el hombre como enfermedad. Los aires pueden ser manipulados también por los brujos.

Desequilibrios religioso-rituales. Dentro de este tipo de desequilibrios, en el cual la autora da cuenta de la noción de enfermedad como resultante de violaciones a tabúes, o incumplimientos rituales, distingue tres subáreas geográficas, según la influencia indígena o europea que predomine. En cuanto al concepto de enfermedad, en la subárea norte, registra la importancia ritual de Pachamama y otras creencias de origen aborigen en las cuales si no se cumple con su devoción puede provocar enfermedades tales como la sopladura -manifiesta en problemas dérmicos y/u óseos de diversa gravedad, la agarradura- causada por la sustracción de la energía vital en tanto entidad de la persona. En la subárea central van desapareciendo las representaciones relativas a la Pachamama y se manifiestan ideas con fundamento en las creencias del catolicismo. En la subárea sur, el concepto de enfermedad se asocia a una falta de reciprocidad hacia los santos populares, conducta manifiesta en el incumplimiento ritual.

\section{Tercera Parte: Los caminos terapéuticos y el punto de vista del usuario}

En esta tercera parte, la autora describe tres niveles en el análisis de satisfacción del usuario, variable que en los últimos años se ha comenzado a utilizar en la medición de calidad de la atención en salud. Un nivel 
individual, que refiere a la personalización en la atención, un nivel institucional, respecto a la presencia o no de establecimientos de salud, y un nivel colectivo, relacionado con la disposición de los servicios por parte de los usuarios.

Señala Idoyaga Molina que la encuesta, técnica de carácter cuantitativo utilizado corrientemente en los estudios de calidad, presenta una serie importante de limitaciones en lo que hace al conocimiento, conducta concreta y real de la población y en la atención de la salud, en contextos multiétnicos e interculturales. Propone así la necesidad de utilizar técnicas cualitativas, como entrevistas abiertas extensas y recurrentes a informantes calificados, así como conocer los caminos terapéuticos de los usuarios. Técnicas que permiten detectar lo que el paciente busca en cada medicina y la visión global que tiene de ellas.

\section{Los caminos terapéuticos: un aborde cualitativo}

Dichos caminos son, a criterio de la autora, el contexto amplio en que se deben evaluar las prestaciones y ofertas. En el proceso de selección de la terapia influyen factores estructurales y coyunturales (Fassin 1992) así como las características de la población y la oferta de medicinas existentes. La autora desarrolla las preferencias por tipo de medicina según la región, sustentada en las diferentes representaciones acerca de la enfermedad y la salud, la persona, las entidades que la conforman, y la terapia, señalando los límites que la misma biomedicina impone.

Surgen así los caminos terapéuticos como una alternativa lógica y no como persistencia de nociones ancestrales de la población, recorridos que se multiplicarán cuando el mal persista.

Refiere la autora el carácter dinámico del diagnóstico y la percepción de la enfermedad, desde la perspectiva del usuario, donde el desenlace de la misma permite refigurar el proceso completo desde el inicio. Sólo el tratamiento efectivo convalida un diagnóstico biomédico; por el contrario, tratamiento efectivo y muerte también convalidan el diagnóstico realizado por el curandero, según el mal detectado. La autora enumera luego diversas causas que producen el alejamiento del usuario de la biomedicina, entre ellas el uso del vocabulario técnico como manejo de poder, la cantidad y complejidad de análisis que se requieren para realizar un diagnóstico presuntivo, suceso percibido en el usuario como falta de conocimiento del biomédico, así como la falta de noción de efecto secundario, el cual es reelaborado muchas veces como enfermedad, desde la perspectiva del usuario.
A las citadas causas se suman la descalificación sufrida por los usuarios y la falta de acceso y disponibilidad del servicio, tanto en centros urbanos como en áreas rurales.

Lo que el paciente requiere es un buen diagnóstico, es decir, aquel seguido por un tratamiento que restaura la salud, así como calidad en la atención, comprendido por el usuario como la atención integral de la persona, en sus aspectos físicos, psíquicos y sociales. Refiere la autora que la expresión de insatisfacción de los sectores medios y altos respecto de la biomedicina es similar a la de campesinos y mestizos.

Señala la autora que, tanto entre campesinos como entre individuos instruidos y citadinos, la duración del mal incide también en la cantidad de medicinas y terapeutas que se consultan. Los males prolongados se transforman así en verdaderos itinerarios en búsqueda de diagnóstico y tratamiento efectivo.

Las representaciones en que se inscriben las ideas de enfermedad, terapia y prevención de la medicina tradicional y de la biomedicina, implican lógicas y paradigmas diferentes. Lo que genera una brecha entre trabajadores de la salud y usuarios, brecha que sólo podrá ser zanjada a través de la capacitación de los primeros, pero también, y especialmente, a través de la implementación de la complementariedad terapéutica. Estas representaciones y las diferencias en los modos de pensar la enfermedad y la terapia son de importancia a la hora de comprender la conducta de la población con relación a la biomedicina, a sus servicios y a los modos en que los evalúan. Esta fractura entre las nociones de salud y enfermedad se transforma en una ruptura sobre la noción de satisfacción, de necesidades y demandas.

Los límites de la biomedicina coinciden con los límites de su modelo dominante, con la manera en que define a la enfermedad y la terapia. Así es que, a partir de la preferencia de los usuarios por otras medicinas que ofrecen una comprensión global del hombre, se estructura en la realidad un sistema etnomédico en la atención de la salud, el cual funciona con total independencia de lo que el sistema oficial de salud acepte o reconozca como adecuado y legal.

En síntesis, el trabajo de Idoyaga Molina se presenta como una importante contribución al campo de la antropología médica, al develar la diversidad de nociones sobre la etiología y manifestaciones de la enfermedad entre los campesinos de las regiones del NOA y Cuyo de la Argentina, proponiendo una clasificación que rescata la perspectiva de los actores, al mismo tiempo que muestra la plena vigencia de un sistema etnomédico. 


\section{Referencias Citadas}

Fassin, D.

1992 Pouvoir et Maladie en Afrique. Paris: PUF.

Good, $\mathrm{CH}$

1987 Ethnomedical Systems in Africa. New York: The Guilford Press.

Idoyaga Molina, A.

1997a Ethnomedicine and world-view. A comparative analysis of the rejection and incorporation of the contraceptive methods among Argentine women. Anthropology and Medicine 4 (2).
1998 Núcleos del conflicto entre la medicine científica y las medicinas tradicionales en la Argentina. The Journal of Intercultural Studies 25.

Laplantine

1999 Antropología de la Enfermedad. Estudio Etnológico de las Representaciones Etiológicas y Terapéuticas en la Sociedad Occidental Contemporánea. Buenos Aires: Ediciones del Sol. 